\title{
Pre-term Infants in Major Abdominal Surgery and Postoperative Outcome
}

Claudine Kumba ( $\sim$ claudine.kumba@gmail.com )

Hôpital Universitaire Necker Enfants Malades, Assistance Publique Hôpitaux de Paris, APHP, Université de Paris https://orcid.org/0000-0002-9748-5141

\section{Research Article}

Keywords: Pre-terms, Major Abdominal Surgery, Outcome

Posted Date: June 30th, 2021

DOI: https://doi.org/10.21203/rs.3.rs-669064/v1

License: (a) (i) This work is licensed under a Creative Commons Attribution 4.0 International License. Read Full License 


\section{Abstract}

Background: A monocentric observational study was undertaken in pediatric surgical patients in neurosurgery, abdominal and orthopedic surgery to determine predictors of postoperative outcome. In this cohort of 594 patients with a mean age of $90.86 \pm 71.80$ months there were 25 pre-terms aged less than 37 weeks. A description of postoperative outcome was undertaken in these pre-term infants.

Objective: The objective of this study was to describe the characteristics in pre-term patients in this initial cohort.

Methods: Secondary analysis of pre-term patients included in the initial retrospective observational study. The Ethics Committee approved the study.

Results: 25 pre-terms aged <37 weeks were included with a mean weight of $2.43 \pm 0.75 \mathrm{~kg}$ in major neonatal abdominal surgery. 9 patient presented postoperative complications among which 1 had an intra-operative cardiac arrest, 4 had postoperative respiratory failure, 2 had pulmonary sepsis, 1 had surgical wound sepsis, 1 had septicemia and 1 had multi-organ sepsis.

Conclusion: In this cohort of 25 critically ill pre-terms in major neonatal abdominal surgery, the most common postoperative complications concerned the respiratory system which included respiratory failure and pulmonary sepsis. There was no in-hospital mortality.

\section{Introduction}

In 2017, a monocentric observational retrospective study was undertaken in pediatric surgical patients in neurosurgery, abdominal and orthopedic surgery to determine predictors of postoperative outcome (1). In this cohort of 594 patients with a mean age of $90.86 \pm 71.80$ months, there were 25 pre-term infants aged less than 37 weeks. These were all admitted in the neonatal intensive care unit (NICU) and were scheduled for emergency and elective surgery. These pre-term patients were described in detail in this manuscript. The objective of this study was to describe the characteristics and postoperative outcome in these pre-term infants in this cohort.

\section{Methods}

Secondary analysis and description of pre-term patients included in the initial retrospective observational study from 1 January 2014 to 17 May 2017 (1). This study was declared to the CNIL, National Commission for Computer Science and Liberties on 21 February 2017 under the registration number 2028257 v0 and received approval from the Ethics Committee of Necker on 21 March 2017 under the registration number 2017-CK-5-R1 (1).

Inclusion criteria were patients aged less than 37 weeks included in the initial study.

Exclusion criteria were patients aged more than 37 weeks included in the initial study.

Statistics were analyzed with XLSTAT 2020.4.1 software.

Continuous variables were described in means with standard deviation or in medians with

interquartile range. Categoric variables were described in proportions. Categoric variables were compared with Fischer's exact test.

\section{Results:}

General characteristics are illustrated in Table 1. 
Table 1

General Characteristics of preterm infants admitted in NICU after abdominal surgery

\begin{tabular}{|c|c|}
\hline Characteristics & $\mathrm{N}=\mathbf{2 5}$ \\
\hline Age & $<37$ weeks \\
\hline Mean Weight \pm standard deviation in kilograms & $2.43 \pm 0.75$ \\
\hline ASA III n (\%) & $20(80)$ \\
\hline ASA IV n (\%) & $5(20)$ \\
\hline Median LOSICU [interquartile range] in days & $33[20-45]$ \\
\hline Median LOS [ interquartile range] in days & $6[0-26]$ \\
\hline Median TLOS [interquartile range] in days & $45[32-54]$ \\
\hline Median LMV [interquartile range ] in days & $4[3-8]$ \\
\hline Median preoperative hemoglobin levels [interquartile range] in $\mathrm{g} / \mathrm{dL}$ & $16.5[15-17.5]$ \\
\hline Median postoperative hemoglobin levels [interquartile range] in $\mathrm{g} / \mathrm{dL}$ & $15.25[14.2-18.2]$ \\
\hline Postoperative mechanical ventilation n (\%) & $22(88)$ \\
\hline Emergency surgery $\mathrm{n}(\%)$ & $19(76)$ \\
\hline Elective surgery $\mathrm{n}(\%)$ & $6(24)$ \\
\hline Transfusion n (\%) & $0(0)$ \\
\hline Patients with postoperative complications n (\%) & $9(36)$ \\
\hline In-Hospital mortality n (\%) & $0(0)$ \\
\hline Re-surgery n (\%) & $4(16)$ \\
\hline Intra-operative cardiac arrest n (\%) & $1(4)$ \\
\hline Postoperative respiratory failure $\mathrm{n}(\%)$ & $4(16)$ \\
\hline Postoperative pulmonary sepsis n (\%) & $2(8)$ \\
\hline Postoperative surgical wound sepsis $\mathrm{n}(\%)$ & $1(4)$ \\
\hline Postoperative septicemia n (\%) & $1(4)$ \\
\hline Postoperative multi-organ sepsis n (\%) & $1(4)$ \\
\hline Intestinal Exeresis for enterocolitis n (\%) & $1(4)$ \\
\hline Exploratory laparotomy for volvulus n (\%) & $1(4)$ \\
\hline Exploratory Laparotomy n (\%) & $3(12)$ \\
\hline Gastroschisis n (\%) & $8(32)$ \\
\hline Omphalocele n (\%) & $4(16)$ \\
\hline Esophageal Atresia n (\%) & $8(32)$ \\
\hline \multicolumn{2}{|l|}{$\mathrm{N}=$ total number of patients } \\
\hline $\mathrm{n}=$ number of patients with the variable & \\
\hline
\end{tabular}

25 pre-terms aged $<37$ weeks were included.

Mean weight was $2.43 \pm 0.75 \mathrm{~kg}$. There were 20 ASA III and 5 ASA IV patients.

Surgery concerned 1 intestinal resection for enterocolitis, 1 exploratory laparotomy for volvulus, 3

exploratory laparotomies, 8 gastroschisis, 4 omphaloceles and 8 esophageal atresias.

19 patients underwent emergency surgery and 6 underwent elective surgery.

1 patient had a congenital heart disease and 1 had a right atrium thrombus.

4 patients had re-operations.

9 patients presented postoperative complications among which 1 had an intra-operative cardiac 
arrest with favorable outcome, 4 had postoperative respiratory failure, 2 had pulmonary sepsis, 1

had surgical wound sepsis, 1 had septicemia, 1 had multi-organ sepsis.

There was no in-hospital mortality.

All were admitted in the NICU, 22 patients were under mechanical ventilation postoperatively and 3

did not require postoperative mechanical ventilation.

Median neonatal intensive care unit stay (LOSICU) was 33 days [20-45], median hospital length stay

(LOS) was 6 days [0-26], median total hospital length stay, TLOS (LOSICU + LOS) was 45 days[32-54]

and median length of mechanical ventilation (LMV) was 4 days [3-8].

None received transfusion.

Median preoperative and postoperative hemoglobin levels were $16.5 \mathrm{~g} / \mathrm{dL}[15-17.5]$ and

$15.25 \mathrm{~g} / \mathrm{dL}[14.2-18.2]$ respectively.

Table 2 illustrates complications in each surgical intervention and there was no difference among

Table 2

Outcomes per type of surgery

\begin{tabular}{|c|c|c|c|c|c|c|c|c|c|}
\hline & Surgery & $\begin{array}{l}\text { Intra- } \\
\text { operative } \\
\text { cardiac } \\
\text { arrest }\end{array}$ & $\begin{array}{l}\text { Postoperative } \\
\text { Respiratory } \\
\text { failure }\end{array}$ & $\begin{array}{l}\text { Postoperative } \\
\text { Pulmonary } \\
\text { sepsis }\end{array}$ & $\begin{array}{l}\text { Postoperative } \\
\text { Surgical } \\
\text { wound sepsis }\end{array}$ & $\begin{array}{l}\text { Postoperative } \\
\text { Septicemia }\end{array}$ & $\begin{array}{l}\text { Postoperative } \\
\text { Multi-organ } \\
\text { sepsis }\end{array}$ & $\begin{array}{l}\mathrm{Re}- \\
\text { Surgery }\end{array}$ & $\begin{array}{l}\text { Total } \\
\text { complications } \\
\text { (intra- } \\
\text { operative, } \\
\text { postoperative } \\
\text { and re- } \\
\text { surgery) per } \\
\text { type of } \\
\text { surgery }\end{array}$ \\
\hline $\begin{array}{l}\text { Intestinal } \\
\text { exeresis for } \\
\text { enterocolitis }\end{array}$ & 1 & 0 & 0 & 0 & 0 & 0 & 0 & 0 & 0 \\
\hline $\begin{array}{l}\text { Exploratory } \\
\text { laparotomy } \\
\text { for volvulus }\end{array}$ & 1 & 0 & 0 & 0 & 0 & 0 & 0 & 0 & 0 \\
\hline $\begin{array}{l}\text { Exploratory } \\
\text { laparotomy }\end{array}$ & 3 & 0 & 0 & 1 & 0 & 0 & 0 & 0 & 1 \\
\hline Gastroschisis & 8 & 0 & 0 & 0 & 1 & 0 & 1 & 3 & 5 \\
\hline Omphalocele & 4 & 0 & 1 & 1 & 0 & 1 & 0 & 1 & 4 \\
\hline $\begin{array}{l}\text { Esophageal } \\
\text { atresia }\end{array}$ & 8 & 1 & 3 & 0 & 0 & 0 & 0 & 0 & 4 \\
\hline Total & 25 & 1 & 4 & 2 & 1 & 1 & 1 & 4 & 14 \\
\hline
\end{tabular}

different types of surgery.

\section{Discussion}

The rate of patients with postoperative complications in this cohort is comparable to what has been

reported in neonatal infants in abdominal major surgery $(2,3,4,5)$. There was no significant

difference in complication rates among different types of surgery. One patient presented intra-

operative cardiac arrest with favorable outcome which represented $4 \%$ of the complications. The

incidence of intra-operative cardiac arrest was $0.12 \%$ according to a recent study in a cohort of 5609

infants aged up to 60 weeks among which $35.7 \%$ were pre-terms (6). According to this same study,

the rate of patients with intra-operative critical events was $35.5 \%$ among which the majority were 
commonly due to cardiovascular instability followed by hypoxemia; $16.3 \%$ of the patients had one or several postoperative critical events (6). In our study, intra-operative critical events concerned one patient who presented intra-operative cardiac arrest representing $4 \%$ of the patients. The rate of patients with postoperative complications until discharge from hospital was $36 \%$ in our cohort. Our study of 25 pre-terms in major abdominal surgery revealed that the most common postoperative complications concerned the respiratory system which included respiratory failure and pulmonary sepsis with an overall rate of $24 \%$. According to previous studies in 198 infants with esophageal atresia and 44 pre-terms with gastroschisis, the rate of postoperative respiratory dysfunction varied between $11 \%$ and $52.8 \%(2,3)$. The second common postoperative complication in our cohort was re-operation (16\%) followed by surgical wound sepsis (4\%), septicemia (4\%) and multi-organ sepsis (4\%). Re-surgery rates varied from 5 to $11.7 \%$ according to one study in 3479 infants with esophageal atresia (4). Sepsis after major surgery such as esophageal atresia has been reported to vary between $3.1-19.4 \%$ (2). In this cohort, the overall sepsis rate was $20 \%$ with pulmonary sepsis being the most common with a rate of $8 \%$. The incidence of early onset sepsis (appearing after less than 3 days of life) in pre-terms varied from 0.5 to $2.5 \%$ according to one study (7) and the rate of late onset sepsis (appearing after 3 days of life) in pre-terms varied from 11-32\% $(8,9)$. Neonatal sepsis is a major etiology of morbi-mortality in pre-terms $(7,8)$. Mortality rates due to sepsis in pre-terms can reach $20-30 \%(10)$. In our cohort, there was no mortality. Mortality rates reported in the literature in pre-terms scheduled for major neonatal abdominal surgery such as necrotizing enterocolitis, esophageal atresia, gastroschisis and omphalocele varied between 3.4 and $34 \%(2,3,5,11,12,13,14)$. According to a study in 75 neonates with abdominal wall defects, mortality was higher in patients with associated congenital heart diseases and chromosomic disorders (14). In another study of 1554 premature infants in emergency abdominal operations, female gender, inotropic support, mechanical ventilation and ASA score III were predictors of 30 days mortality (15). In a study of 566 neonates with gastroschisis, the presence of a complex laparoschisis, pre-term age of $<37$ weeks, very low birth weight of $<1500$ grams were factors predicting morbi-mortality (16). According to the multicentric Nectarine study, overall mortality rate was $3.2 \%$, with a 30 -day mortality rate in neonates of $4.1 \%$ with sepsis and multi-organ failure being major causes of mortality in this subgroup (6). The Nectarine study which included patients aged up to 60 weeks admitted for different surgical interventions revealed that age, critical events including hypotension, hypoxemia and anemia were predictive of adverse outcome illustrated by morbi-mortality (6). In our pre-term cohort, none of the patients were anemic and none received transfusion. Our initial monocentric retrospective study of 594 patients admitted for neurosurgery, abdominal and orthopedic surgery with a mean age of $90.86 \pm 71.80$ months from which this pre-term cohort sample was extracted evidenced that the general patient's status, precisely the ASA (American Society of Anesthesiologists) scores III, IV and V were predictive of mortality (1). All pre-term infants in this 
cohort were ASA III or IV. This retrospective study revealed also that ASA score III or more,

transfusion, emergency situations, age and the type of surgery were predictive of postoperative organ dysfunction (1). In this study (1), ASA score, transfusion, emergency, type of surgery and preterm age were predictive of LOSICU and LMV. Median LOS, LOSICU and LMV in our study were comparable to what has been reported (16).

Median total hospital length of stay, TLOS (LOSICU + LOS) was 45 days[32-54] and was comparable to what has been reported in the literature (13). In a study of 442 neonates with gastroschisis of more than 34 weeks of age (17), median LOS was higher in patients with staged closure than in primary closure, implying that LOS is a variable which depends on other factors. In our retrospective study, LOS was predicted by ASA score, transfusion, emergency and the type of surgery (1).

The results of our initial pediatric retrospective study (1), the results of the Nectarine study (6) and the results of previous studies in similar neonatal population $(14,15,16,17)$ confirm that outcome in the surgical pediatric population is multifactorial. Identifying these multiple predictors of adverse evolution and applying preventive and improvement measures on each of them can optimize postoperative outcome in children. A meta-analysis in 3290 children aged less than 18 years old evidenced that mortality, organ dysfunction and LOS were lower in children who had optimal intraoperative or postoperative values of regional oxygen saturation, mixed central venous oxygen saturation and lactate levels (18). Regional oxygen saturation, mixed central venous oxygen saturation and lactate levels reflect tissular perfusion and alterations of these parameters can indicate tissular perfusion impairment which can cause organ dysfunction.

The results of this study confirm that the rate of postoperative complications in critically ill pre-term infants in major abdominal surgery remains high as reported by previous studies. This emphasizes optimizing intra-operative fluid and hemodynamic status to improve postoperative evolution in highrisk patients. However other factors which predict postoperative adverse outcome should be taken into account to improve outcome and intra-operative optimization is one among these predictors.

The limit of our study was the sample size.

The strength of our study was the homogeneity of the sample which included critically ill pre-term infants in major abdominal surgery thus a high-risk population.

\section{Conclusion}

In this study of 25 critically ill pre-term infants admitted in NICU after abdominal major surgery, the most common postoperative complications concerned the respiratory system which included respiratory failure and pulmonary sepsis; followed by re-surgery, wound sepsis, septicemia and multi-organ sepsis. There was no in-hospital mortality. Maintaining adequate tissular perfusion is necessary for optimal outcome in surgical pediatric patients. This aim can be achieved by intra-operative fluid and hemodynamic optimization by using means to monitor adequate tissular perfusion. These means should be adapted according to the context which includes patient status, age and surgery.

\section{Declarations}


Ethics approval and informed consent: This study received approval from the Ethics Committee of Necker on 21 March 2017 under the registration number 2017-CK-5-R1. The Ethics Committee of Necker waived the need for patient consent since this was a retrospective study.

Competing of interests: The author declared no conflict of interest

Author's contribution: Dr Claudine Kumba conceptualized and designed the study, drafted the initial and final manuscript. She designed the data collection instruments, collected data, carried out initial and final analyses

Funding: There was no funding

Presentation of preliminary data: The abstract of this study has been accepted for presentation to the European Congress of Pediatric and Neonatal Intensive Care 15-18 June 2021.

\section{References}

1. Kumba C, Cresci F, Picard C et al. Transfusion and Morbi-Mortality Factors: An Observational Descriptive Retrospective Pediatric Cohort Study. J Anesth Crit Care Open Access 2017; 8(4): 00315. DOI:10.15406/jaccoa.2017.08.00315.

2. Li XW, Jiang YJ, Wang XQ et al. A scoring system to predict mortality in infants with esophageal atresia. A case-control study. Medicine 2017 ; 96:32(e7755). http://dx.doi.org/10.1097/MD.0000000000007755.

3. Tsai MH, Huang HR, Chu SM et al. Clinical Features of Newborns With Gastroschisis and Outcomes of Different Initial Interventions: Primary Closure Versus Staged Repair. Pediatr Neonatol 2010;51(6):320-325.

4. Sulkowski JP, Cooper JN, Lopez JJ et al. Morbidity and Mortality in Patients with Esophageal Atresia. Surgery 2014; 156(2): 483-491. doi:10.1016/j.surg.2014.03.016.

5. Sheng Q, Lv Z, Xu W et al. Short-term surgical outcomes of preterm infants with necrotizing enterocolitis. Medicine 2016; 95:30(e4379). http://dx.doi.org/10.1097/MD.0000000000004379

6. Disma N, Veyckemans F, Virag K, Hansen TG et al. Morbidity and mortality after anaesthesia in early life: results of the European prospective multicentre observational study, neonate and children audit of anaesthesia practice in Europe (NECTARINE). Br J Anaesth 2021; doi:10.1016/j.bja.2021.02.016.

7. Puopolo KM, Mukhopadhay S, Hansen NI, Cotten CM et al. Identification of extremely premature infants at low risk for early-onset sepsis. Pediatrics 2017; 140(5): e20170925. doi: 10.1542/peds.2017-0925.

8. Downey LC, Smith PB, Benjamin DK. Risk Factors and prevention of late onset sepsis in premature infants. Early Hum Dev 2010; 86(1): 7-12. doi:10.1016/j.earlhumdev.2010.01.012.

9. Alock G, Liley HG, Cooke L, Gray PH. Prevention of neonatal late-onset sepsis: a randomized controlled trial. BMC Pediatrics 2017 ; 17:98. DOI 10.1186/s12887-017-0855-3.

10. Mukhopadhyay S, Puopolo KM. Risk assessment in neonatal early-onset sepsis. Semin Perinatol. 2012; 36(6): $408-415$. doi:10.1053/j.semperi.2012.06.002.

11. Bauman B, Stephens D, Gershone H, Bongiorno C, Osterholm E, Acton R et al. Management of giant omphaloceles: A systematic review of methods of staged surgical vs. nonoperative delayed closure. J Pediatr Surg 2016; 51: 1725-1730. http://dx.doi.org/10.1016/j.jpedsurg.2016.07.006.

12. Kelay A, Durkin N, Davenport M. Congenital Anterior Abdominal Defects. Surgery 2016;34:12.

13. Bhat V, Moront M, Bhandari V. Gastroschisis: A State-Of-The-Art Review. Children 2020, 7, 302; doi:10.3390/children7120302.

14. Mayer T, Black R, Matlak M, Johnson D. Gastroschisis and omphalocele. An Eight-year review. Ann Surg 1980; 192(6):783-787.

15. Cairo SB, Tabak BD, Berman L et al. Mortality after emergency abdominal operations in premature infants. J Pediatr Surg 2013; 53: $2105-2111$.

16. Raymond SL, Hawkins RB, St. Peter SD et al. Predicting Morbidity and Mortality in Neonates born with Gastroschisis. J Surg Res 2020; $245:$ 217-224.

17. Murthy K, Evans JR, Bhatia AM et al. The association of type of surgical closure on length of stay among infants with gastroschisis born $>34$ weeks gestation. J Pediatr Surg 2014; 49:1220-1225.

18. Kumba C, Willems A, Querciagrossa S et al. A Systematic Review and Meta- Analysis of Intraoperative Goal Directed Fluid and Haemodynamic Therapy in Children and Postoperative Outcome. J Emerg Med Critical Care 2019;5(1):1-9. DOI: 10.13188/2469-4045.1000020. 